\title{
Transport of Proteins into Mitochondria: Translocational Intermediates Spanning Contact Sites between Outer and Inner Membranes
}

\author{
Manfred Schleyer* and Walter Neupert \\ Institut für Physiologische Chemie \\ Physikalische Biochemie und Zellbiologie \\ der Universität München \\ Goethestrasse 33 \\ 8000 München 2, Federal Republic of Germany
}

\section{Summary}

Translocational intermediates of precursor proteins of ATPase $F_{1} \beta$ subunit and cytochrome $c_{1}$ across mitochondrial membranes were analyzed using two different approaches, transport at low temperature and transport after binding of precursor proteins to antibodies. Under both conditions precursors were partially transported into mitochondria in an energydependent manner. They were processed by the metalloprotease in the matrix but a major proportion of the polypeptide chains was still present at the outer face of the outer mitochondrial membrane. We conclude that transfer of precursors into the inner membrane or matrix space occurs through "translocation contact sites"; precursor polypeptides to $F_{1} \beta$ and cytochrome $c_{1}$ enter the matrix space with the amino terminus first; and a membrane potential is required for the transmembrane movement on an aminoterminal "domain-like" structure but not for completing translocation of the major part of the polypeptides.

\section{Introduction}

During recent years several basic features of the import of cytoplasmically synthesized proteins into mitochondria have been established (for review see Schatz and Butow, 1983; Hay et al., 1984; Harmey and Neupert, 1985). These proteins are translated on free ribosomes and released as completed polypeptide chains into the cytosolic compartment. In most cases, but not all, these cytosolic precursor proteins carry amino-terminal polypeptide extensions. The precursors are thought to bind to receptors on the surface of the mitochondria (Hennig et al., 1983; Zwizinski et al., 1984). In a subsequent step the precursors are translocated across the mitochondrial membranes. The additional sequence is then removed by a matrix-located processing peptidase (Böhni et al., 1980; Miura et al., 1982; Conboy et al., 1982; McAda and Douglas, 1982; Schmidt et al., 1984). The translocation into or across the inner mitochondrial membrane is dependent on a mitochondrial membrane potential (Schleyer et al., 1982; Gasser et al., 1982a; Kolansky et al., 1982).

A detailed understanding of the reactions between the binding of the precursor to the receptor on the mitochondrial surface and the cleavage of the additional sequence

\footnotetext{
* Present address: Department of Biochemistry, University of California Berkeley, Berkeley, California 94720.
}

in the matrix space is yet to be obtained. It is an open question as to how the precursor polypeptide is translocated across the membranes, particularly whether the precursor is transported in a globular or unfolded state. Another unsolved problem is the mechanism by which proteins such as the $F_{1}$-ATPase subunits (which are completely transferred across both outer and inner membranes to a location in the matrix) traverse the two mem. branes: is transfer accomplished in two separate steps or in a single step via "fusion" or "contact" sites?

In an attempt to identify further intermediate reactions in this part of the transport pathway, we have studied the temperature dependence of the transfer of the precursors to $F_{1}$-ATPase $\beta$ subunit and to cytochrome $c_{1}$ into isolated Neurospora mitochondria. We report here that below a temperature of around $11^{\circ} \mathrm{C}$, the precursors are translocated partially into the mitochondria in such a fashion that they become processed by the matrix processing peptidase, but with a major part of the precursor remaining outside the mitochondrion. The transport into this intermediate location is dependent on the membrane potential. These intermediates can be chased into a protease protected form by raising the temperature to $25^{\circ} \mathrm{C}$. This latter step is not dependent on a membrane potential. Also, the precursor proteins accumulate at such an intermediate location if they are prebound to their corresponding antibodies before transport into the mitochondria. We interpret these data to show that intermediates on their way across the membrane can be trapped and analyzed, that the mitochondrial membrane potential is only required for the translocation of the amino-terminal part of the precursor, and that "translocation contact sites" exist in the mitochondria, in which outer and inner membranes come so close together that they can be spanned by the precursor polypeptide chains.

\section{Results}

Precursors to $F_{1} \beta$ and Cytochrome $c_{1}$ Are Incompletely Transported across the Membranes of Isolated Mitochondria at Low Temperature

Transport of Neurospora $F_{1} \beta$ precursor (pre- $F_{1} \beta$ ) into isolated mitochondria was studied at various temperatures between $0^{\circ} \mathrm{C}$ and $25^{\circ} \mathrm{C}$. Mitochondria were incubated in a postribosomal supernatant of a reticulocyte lysate containing ${ }^{35} \mathrm{~S}$-labeled precursors and then re-isolated. $\mathrm{F}_{1} \beta$ was immunoprecipitated after lysis of mitochondria with Triton X-100 and analyzed by gel electrophoresis. Association of pre- $F_{1} \beta$ with mitochondria as well as proteolytic processing occurred at all temperatures (Figure 1A). Processing to mature sized $F_{1} \beta\left(m-F_{1} \beta\right)$ was inhibited when the mitochondrial membrane potential was destroyed by the addition of antimycin $A$ and oligomycin. Since the processing peptidase is located in the matrix (Böhni et al., 1980; Miura et al., 1982; Conboy et al., 1982; Schmidt et al., 1984), this means that the cleavage site of the precursor had traversed the inner membrane even at low tem- 
A
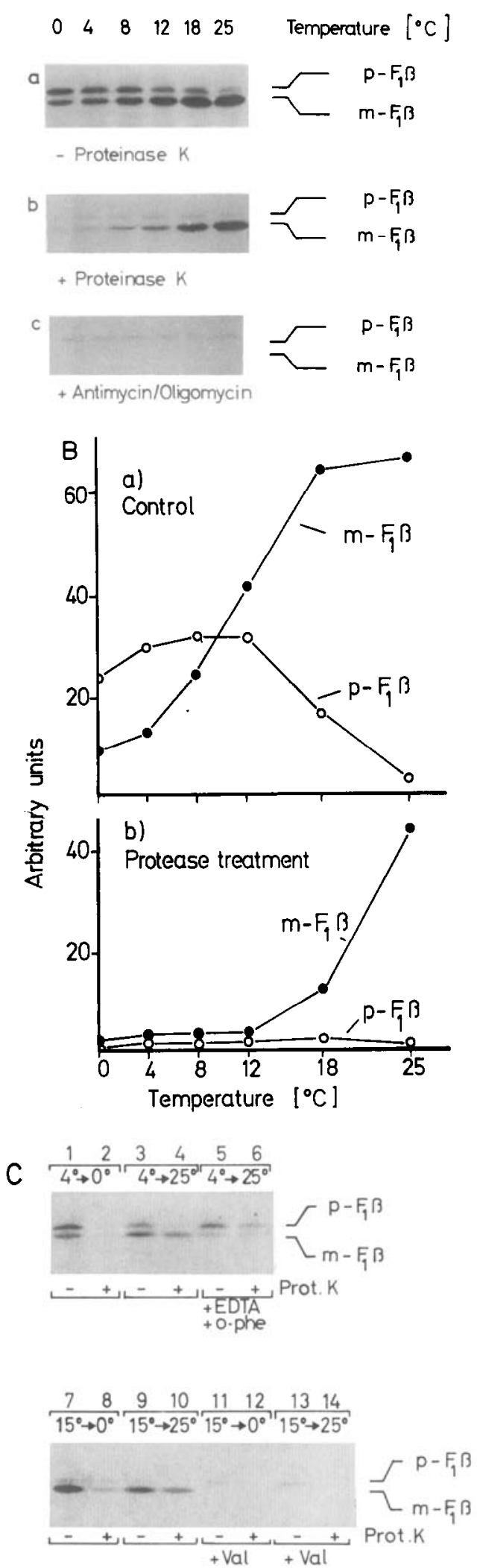

Figure 1. Temperature Dependence of in Vitro import of $F_{1} \beta$ into Mitochondria

(A) Neurospora poly(A) RNA was translated in reticulocyte lysate in the presence of $\left({ }^{35} \mathrm{~S}\right)$ methionine. A postribosomal supernatant was pre- peratures. However, only when the transfer had been carried out at higher temperature was the $m-F_{1} \beta$ largely resistant to proteinase $K$ added to the incubation mixture at the end of the transfer reaction (Figure $1 \mathrm{~A}$ ). This protease resistance is taken as a criterion that complete transfer of the precursor has occurred into the matrix space, or at least across the outer mitochondrial membrane. A quantitative evaluation of the data is presented in Figure $1 \mathrm{~B}$. The $\mathrm{m}-\mathrm{F}_{1} \beta$ imported at $25^{\circ} \mathrm{C}$ was largely, but not always completely, resistant to the added protease (see also below, Figure 3 ). Part of the $m-F_{1} \beta$ appears to be incompletely translocated into the mitochondria even at $25^{\circ} \mathrm{C}$. There may be other factors besides low temperature that lead to incomplete transfer.

It should be noted that at low temperature, we always observed more pre- $F_{1} \beta$ associated with mitochondria in the presence of a membrane potential than in the absence of a potential. This suggested that part of the incompletely translocated $F_{1} \beta$ was in the precursor form. This was indeed the case, since a large fraction of the pre- $F_{1} \beta$ that accumulated at $4^{\circ} \mathrm{C}$ was processed to $\mathrm{m}-\mathrm{F}_{1} \beta$ even after addition of valinomycin, when the temperature was raised to $25^{\circ} \mathrm{C}$ (Figure $1 \mathrm{C}$ ). The $\mathrm{m}-\mathrm{F}_{1} \beta$ present after incubation at $25^{\circ} \mathrm{C}$ was in a protease protected position. (Valinomycin

pared by centrifugation and supplemented with unlabeled methionine, dithiothreitol, reduced glutathione, sucrose, and NADH (see Experimental Procedures). It was divided into three portions of $300 \mu \mathrm{l}$. Mitochondria from a stock in SET (4 mg protein/ml, kept frozen at $-80^{\circ} \mathrm{C}$ ) were added to a final concentration of $0.2 \mathrm{mg}$ protein $/ \mathrm{ml}$ to all three portions. To the third portion $4 \mu \mathrm{M}$ antimycin $\mathrm{A}$ and $10 \mu \mathrm{M}$ oligomycin were added. Each portion was divided into aliquots of six and these were incubated for $30 \mathrm{~min}$ at $0,4,8,12,17$, and $25^{\circ} \mathrm{C}$, respectively (reactions $1-6$ ). After cooling at $0^{\circ} \mathrm{C}$ for $5 \mathrm{~min}$, to the reactions of the first portion (a, control) and of the third portion (c, no membrane potential), $1 \mathrm{mM}$ PMSF was added. The reactions of the second portion (b, protease treatment) received proteinase $K$ at a final concentration of $5 \mu \mathrm{g} / \mathrm{ml}$. After $20 \mathrm{~min}$ at $0^{\circ} \mathrm{C}$, PMSF was also added to the second portion of the reactions. All additions were made in such a manner that the samples were chemically identical. After a further $5 \mathrm{~min}$ at $0^{\circ} \mathrm{C}$, all reactions were transferred to new Eppendorf cups and mitochondria were pelleted. They were lysed in $1 \%$ Triton X-100, $0.3 \mathrm{M} \mathrm{NaCl}, 5$ $\mathrm{mM}$ EDTA, $10 \mathrm{mM}$ Tris- $\mathrm{HCl}$ (pH 7.4). ATPase subunit $\beta$ was immunoprecipitated using Sepharose bound protein $A$, the precipitate subjected to SDS-gel electrophoresis. A fluorograph of the dried gel is shown.

(B) An experiment performed as described in (A) was quantitatively evaluated by densitometry of the $X$-ray film at $436 \mathrm{~mm}$. In this case freshly isolated mitochondria were used.

(C) Transfer into mitochondria was performed as in (A) (control) using fresh mitochondria and incubation at $4^{\circ} \mathrm{C}$ for $30 \mathrm{~min}$. Then $0.4 \mu \mathrm{M}$ valinomycin was added and the suspension divided into three aliquots. The first aliquot was further incubated at $0^{\circ} \mathrm{C}$ (lanes 1 and 2), the second aliquot at $25^{\circ} \mathrm{C}$ (lanes 3 and 4), and the third at $25^{\circ} \mathrm{C}$ in the presence of $5 \mathrm{mM}$ EDTA and $100 \mu \mathrm{M}$ o-phenanthroline (lanes 5 and 6). After $15 \mathrm{~min}$, one-half of each aliquot (lanes $2,4,6$ ) was treated with $5 \mu \mathrm{g} / \mathrm{ml}$ proteinase $K$ and then from all reactions $F_{1} \beta$ was immunoprecipitated. In a parallel experiment, transfer was performed at $15^{\circ} \mathrm{C}$ in two portions, one in the absence (lanes 7-10) and a second portion in the presence of $0.4 \mu \mathrm{M}$ valinomycin for $30 \mathrm{~min}$ (lanes 11-14). Then valinomycin also was added to the first aliquot. One-half of each portion was incubated at $0^{\circ} \mathrm{C}$ (lanes 7 and 8,11 and 12), the other half at $25^{\circ} \mathrm{C}$ (lanes 9 and 10,13 and 14). In lanes 8 and 10,12 and 14, mitochondria were treated with proteinase $K$ as above. $p-F_{1} \beta$ and $m-F_{1} \beta$, precursor and mature sized forms of $F_{1}-A T P a s e$ subunit $\beta$, respectively. o-phe, o-phenanthroline; val, valinomycin. 

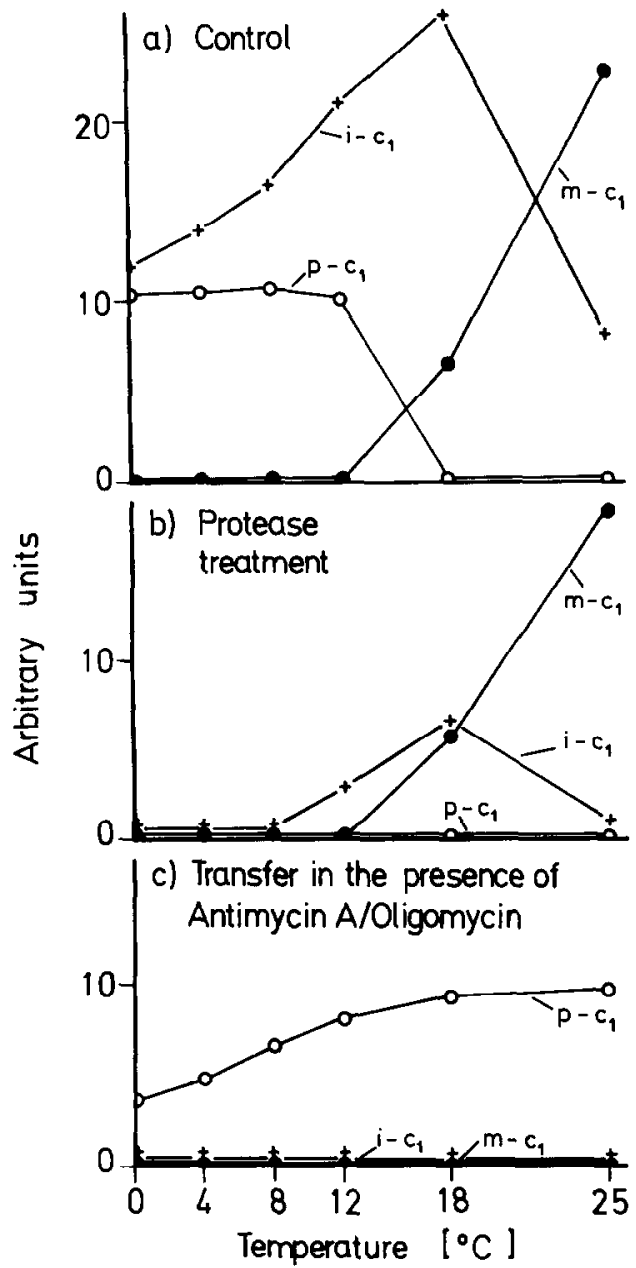

Figure 2. Temperature Dependence of In Vitro Import of Cytochrome $c_{1}$ into Mitochondria

The conditions of the experiment were the same as in Figure 1A. Freshly isolated mitochondria were used in this experiment. Immunoprecipitation was performed with antibodies against cytochrome $c_{1} . p-c_{1}, i-c_{1}$, and $m-c_{1}:$ precursor, intermediate, and mature sized forms of cytochrome $c_{1}$, respectively.

led to a complete block of import and processing, when the $F_{1} \beta$ precursor was added to the extramitochondrial medium or was bound to receptor sites, in confirmation of what we have reported earlier [Schleyer et al., 1982; Zwizinski et al., 1984].) Furthermore, when the temperature was raised to $25^{\circ} \mathrm{C}$ in the presence of o-phenanthroline and EDTA, the pre- $F_{1} \beta$ persisted and became protease protected. Addition of these metal chelators has been shown to inactivate the processing enzyme in the matrix of the mitochondria (Zwizinski and Neupert, 1983). Protease sensitive pre- $F_{1} \beta$, which accumulated at low temperature in the presence of the metal chelators, could be chased after addition of manganese ions to protease sensitive $m-F_{1} \beta$ at a low temperature and to protease resistant $m-F_{1} \beta$ at a higher temperature (not shown). The matrix processing peptidase appears to be involved in the processing observed in the experiments of Figure 1. At low temperatures the activity of the processing peptidase is slowed down, so that it does not process the aminoterminal extrasequences of all the precursor molecules that extend into the matrix space. Most remarkably, the further movement of the translocational intermediates does not require a membrane potential. This will be addressed in detail later.

We then determined whether the $m-F_{1} \beta$ accumulating at low temperature can become protease resistant during a chase at higher temperature. Due to the high percentage of pre- $F_{1} \beta$ accumulated at $4^{\circ} \mathrm{C}$ it could not be excluded from the foregoing experiment that protease resistant $m-F_{1} \beta$ was derived solely from protease sensitive pre- $F_{1} \beta$. Therefore, mainly $\mathrm{m}-\mathrm{F}_{1} \beta$ was produced at $15^{\circ} \mathrm{C}$ and then chased at $25^{\circ} \mathrm{C}$ in the presence of valinomycin. Formation of protease protected $m-F_{1} \beta$ was seen at the expense of protease sensitive $m-F_{1} \beta$ (Figure $1 C$ ).

Transfer of cytochrome $c_{1}$ precursor (pre- $c_{1}$ ) into mitochondria at lower temperature yielded mainly the intermediate sized form (i- $c_{1}$ ) observed earlier (Gasser et al., 1982b; Ohashi et al., 1982; Teintze et al., 1982) (Figure 2a). This first processing step has been shown to be performed by the processing peptidase in the matrix (Gasser et al., 1982b; Teintze et al., 1982). At higher temperatures mainly mature sized cytochrome $c_{1}\left(m-c_{1}\right)$ was formed. At temperatures between $0^{\circ} \mathrm{C}$ and $10^{\circ} \mathrm{C}$, the $\mathrm{i}-\mathrm{C}_{1}$ was virtually completely sensitive to added protease; $i-c_{1}$ formed at $12-18^{\circ} \mathrm{C}$ was partly sensitive. In contrast, $\mathrm{m}-\mathrm{c}_{1}$ was largely resistant to proteinase $K$. In the absence of a membrane potential, processing of pre-c, was completely inhibited at all temperatures. Only precursor was found associated with the mitochondria. These data suggested that at low temperatures the majority of the $\mathrm{i}-\mathrm{c}_{1}$ species was incompletely translocated across the outer mitochondrial membrane.

The i-c, accumulated at $11^{\circ} \mathrm{C}$ could be chased at $25^{\circ} \mathrm{C}$ to protease resistant $m-c_{1}$, if NADH was present. In the absence of NADH, no m-c was formed. If no NADH was present during the initial import reaction, at $25^{\circ} \mathrm{C}$ and at $11^{\circ} \mathrm{C}$ only $\mathrm{i}-\mathrm{C}_{1}$ was formed. The $25^{\circ} \mathrm{C} \mathrm{i}-\mathrm{c}_{1}$, was largely resistant to added protease, however, the $\mathrm{i}-\mathrm{C}_{1}$ accumulated at $11^{\circ} \mathrm{C}$ was not (not shown). These observations demonstrate the existence of different species of $i-c_{1}$, which are apparently located at different steps in the import pathway and which have a different submitochondrial topology. As in the case of $F_{1} \beta$, completion of transfer is not dependent on a membrane potential. The requirement for NADH is unexplained so far.

The experiments in Figures 1 and 2 indicate that a translocational intermediate can be trapped at low temperatures in which a large region of the $F_{1} \beta$ precursor or cytochrome $c_{1}$ precursor is present at the surface of the mitochondria, but with the amino-terminal section exposed on the matrix side of the inner membrane. The question arises as to whether the protease sensitive part of these translocational intermediates is in fact located outside the outer membrane. Since these intermediates are sensitive to added protease this is to be expected. However, the outer membrane of mitochondria may be damaged so that added protease might have degraded translocational intermediates located in the intermembrane space. We therefore studied the intactness of the outer membrane of the mitochondria. The reduction of 


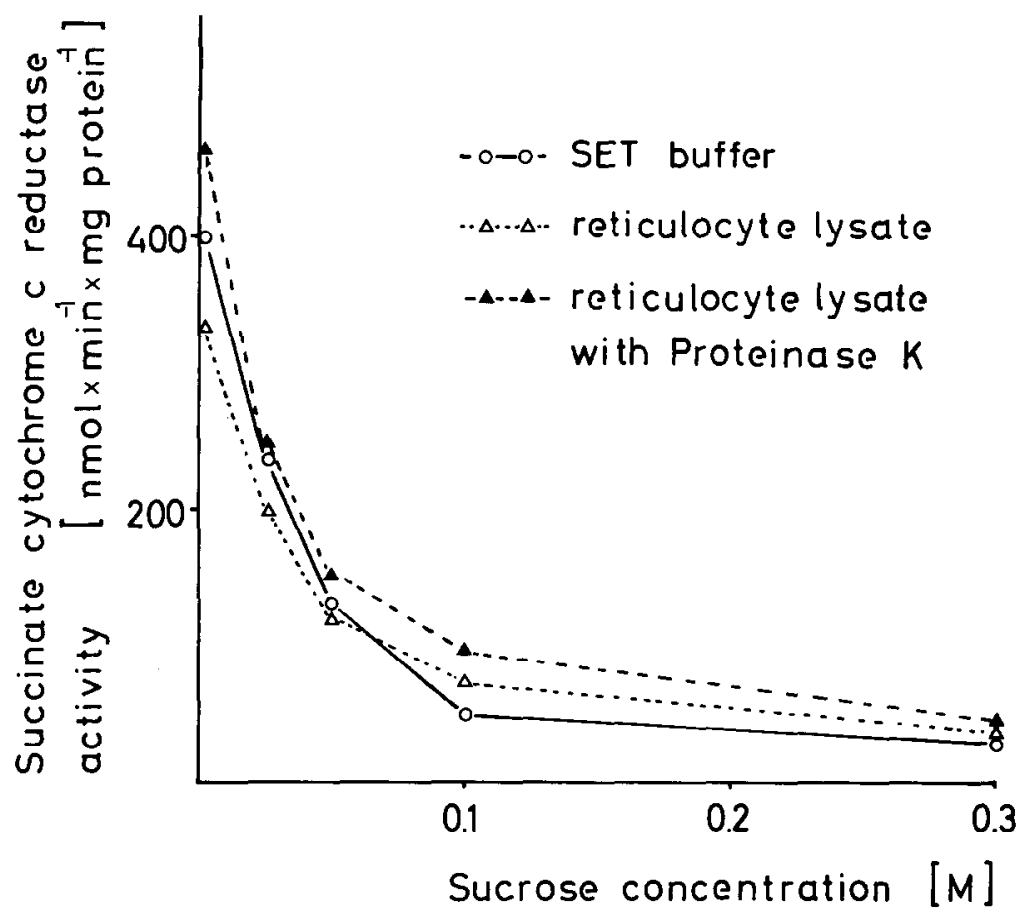

Figure 3. Assessment of Intactness of Mitochondrial Outer Membrane by Monitoring Reduction of Added Cytochrome c

Mitochondria $(0.3 \mathrm{mg}$ protein $/ \mathrm{ml})$ were incubated for $30 \mathrm{~min}$ at $25^{\circ} \mathrm{C}$ in three reactions of $200 \mu \mathrm{l}$ : the first contained SET, the second and third postribosomal supernatant of a reticulocyte lysate supplemented with $50 \mu \mathrm{M}$ methionine, $1 \mathrm{mM}$ dithiothreitol, $5 \mathrm{mM} \mathrm{NADH}$, $5 \mathrm{mM}$ reduced glutathione, and $0.3 \mathrm{M}$ sucrose. After cooling to $0^{\circ} \mathrm{C}$ for $5 \mathrm{~min}$, to the third reaction proteinase $\mathrm{K}$ was added to a final concentration of $5 \mu \mathrm{g} / \mathrm{ml}$. After $20 \mathrm{~min}$ at $0^{\circ} \mathrm{C}, 1 \mathrm{mM}$ PMSF was added to all reactions. The samples were transferred to new Eppendorf cups, and the mitochondria were pelleted and resuspended in $100 \mu \mathrm{l} \mathrm{SET}$. Aliquots were employed for measuring the reduction of added cytochrome $\mathrm{c}$ by succinate via the mitochondrial complex III as described in Experimental Procedures.

added cytochrome $c$ by succinate, via succinate dehydrogenase and complex III of the inner membrane, was used as an assay (Douce et al., 1973). In mitochondria with intact outer membranes no reduction should occur, since the outer membrane is impermeable to cytochrome c (Wojtczak and Zaluska, 1969). In order to have the inner membrane completely accessible to cytochrome c, mitochondria were ruptured by dilution into sucrose-free buffer. Intermediate states were analyzed by adjusting to different sucrose concentrations (Figure 3). Mitochondria incubated in SET were found to have $85 \%-95 \%$ intact outer membrane. Mitochondria recovered after mock incubation in reticulocyte lysate showed an intactness of $60 \%-70 \%$. Inclusion of $1 \mathrm{mM}$ dithiothreitol, $5 \mathrm{mM}$ glutathione, and $5 \mathrm{mM}$ NADH increased this value to $85 \%-$ $90 \%$. Treatment of mitochondria in reticulocyte lysate with proteinase $\mathrm{K}(10 \mu \mathrm{g} / \mathrm{ml})$ did not lead to a decrease of outer membrane intactness.

Protease sensitivity of the $F_{1} \beta$ accumulated at $7^{\circ} \mathrm{C}$ and at $25^{\circ} \mathrm{C}$ was titrated using mitochondria that had been incubated in reticulocyte lysate containing these reducing agents (Figure $4 \mathrm{~A}$ ). $m-\mathrm{F}_{1} \beta$ imported at $25^{\circ} \mathrm{C}$ was largely resistant to the proteinase $\mathrm{K}$ concentrations employed, the degree of resistance varying between $60 \%$ and $100 \%$ at the highest protease concentrations $(10 \mu \mathrm{g}$ proteinase $\mathrm{K}$ or trypsin per $\mathrm{ml})$. In contrast, after transfer at $7^{\circ} \mathrm{C}$ both $m-F_{1} \beta$ and pre- $F_{1} \beta$ were digested at very low concentrations of proteinase $\mathrm{K}$. This was observed when either fresh or frozen mitochondria were used. The translocational intermediates probably have a large portion exposed on the outer face of the outer membrane since no cleavage fragment could be immunoprecipitated. Use of protease from Staphylococcus aureus $\mathrm{V} 8$ did not lead to production of immunoprecipitable fragments either (data not shown).
In Figure 4B the same protease treatment is shown for the various forms of cytochrome $c_{1}$. The pre- $c_{1}$ was largely digested by low concentrations of protease. The same low concentrations also degraded most of the $i-c_{1}$ formed at low temperatures but did not affect the $m-c_{1}$ produced at $25^{\circ} \mathrm{C}$.

To further substantiate the conclusion that the outer membrane is largely intact under the experimental conditions employed, mitochondria were incubated with collodial gold and the distribution of the gold particles (average diameter $5 \mathrm{~nm}$ ) was viewed in thin sections by electron microscopy (Figure 5). The majority of the mitochondria showed intact outer membranes, a condensed matrix, and a wide intermembrane space. Inner membranes apparently adhered to the outer membrane at restricted areas. Gold particles were abundant in the extramitochondrial space and on the surface of the outer membrane. They were not seen in the intermembrane space of mitochondria displaying intact other membranes. Particles could, however, be seen bound to the surface of the inner membrane and between cristae with the few mitochondria that had an apparently opened outer membrane. This supports the conclusion from the biochemical measurements that the majority of the mitochondria have an intact outer membrane that is impermeable to molecules of 4-5 $\mathrm{nm}$ diameter.

We then determined whether the protease sensitive $m-F_{1} \beta$ was present in the soluble or in the membrane fraction of the mitochondria. After transfer at $7^{\circ} \mathrm{C}$ and $25^{\circ} \mathrm{C}$ mitochondria were treated with $0.1 \mathrm{M}$ sodium carbonate to separate soluble and peripheral membrane proteins from integral membrane proteins (Fujiki et al., 1982). At $7^{\circ} \mathrm{C}$, pre- $F_{1} \beta$ and $m-F_{1} \beta$ were found mostly in the membrane fraction (Figure 6). This suggests that the pre- $F_{1} \beta$ and the 


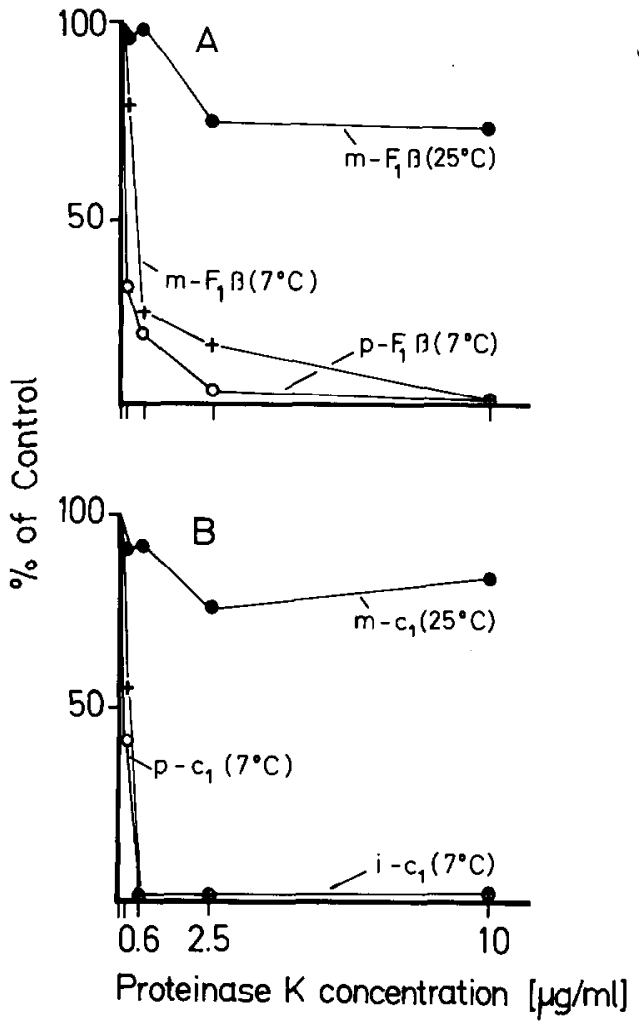

Figure 4. Titration of Protease Sensitivity of $F_{1} \beta$ and Cytochrome $c_{1}$ Transferred into Mitochondria at $7{ }^{\circ} \mathrm{C}$ and at $25^{\circ} \mathrm{C}$

Transfer in vitro was performed in parallel samples at $7^{\circ} \mathrm{C}$ and at $25^{\circ} \mathrm{C}$ as described in Figure 1. Freshly isolated mitochondria were used. After $30 \mathrm{~min}$ the samples were cooled to $0^{\circ} \mathrm{C}$ for $5 \mathrm{~min}$ and divided into aliquots. These aliquots were then incubated with the indicated final concentrations of proteinase $\mathrm{K}$ for $20 \mathrm{~min}$ at $0^{\circ} \mathrm{C}$. Then all aliquots received $1 \mathrm{mM}$ PMSF. After a further $15 \mathrm{~min}$ at $0^{\circ} \mathrm{C}$, mitochondria were re-isolated, lysed, and $F_{1} \beta$ or cytochrome $c_{1}$ were immunoprecipitated employing protein A-Sepharose. Precipitates were subjected to SDS gel electrophoresis and the fluorographs were analyzed by densitometry. $A, F_{1} \beta ; B$; cytochrome $c_{1}$

$\mathrm{m}-\mathrm{F}_{1} \beta$ accumulated at $7^{\circ} \mathrm{C}$ are predominantly membrane integrated. In contrast, import at $25^{\circ} \mathrm{C}$ led to a soluble species of $m-F_{1} \beta$ (see also Zwizinski and Neupert, 1983). These data support the conclusion from the foregoing experiments that at lower temperatures, the $F_{1} \beta$ polypeptides are trapped in the process of moving across the mitochondrial membranes.

With cytochrome $c_{1}$, neither $i-c_{1}$ nor $m-c_{1}$ were extracted with sodium carbonate, in agreement with the supposed membrane integration of both species (not shown).

\section{Only the First Step of Transfer of $F_{1} \beta$ Is Dependent on the Membrane Potential}

Processing of the $F_{1} \beta$ precursor by isolated mitochondria depended on the presence of a mitochondrial membrane potential at all temperatures between $0^{\circ} \mathrm{C}$ and $25^{\circ} \mathrm{C}$. Inclusion of antimycin $\mathrm{A}$ and oligomycin in the transfer reaction led to complete inhibition of processing of pre- $F_{1} \beta$; under these conditions only binding of a very small part of the precursor to the mitochondria was observed. This bound precursor was completely digested by low concentrations of added proteinase K (Figure 1). It is therefore concluded that the step leading to transfer of the amino-terminal portion across the inner membrane is dependent on the membrane potential

In order to determine whether further transfer of $F_{1} \beta$ is also dependent on a membrane potential the following experiment was carried out (Figure 7A). The translocational intermediates were accumulated by incubating mitochondria and reticulocyte lysate at $11^{\circ} \mathrm{C}$ (reactions 3 to 7 ). As a control, incubation was performed at $25^{\circ} \mathrm{C}$ (reactions 1 and 2) and as a further control incubation was done in the presence of $\mathrm{KCN} /$ oligomycin at $25^{\circ} \mathrm{C}$ and at $11^{\circ} \mathrm{C}$ (reactions 2 and 4). KCN/oligomycin inhibited strongly, although not completely, the processing of pre- $F_{1} \beta$. (KCN does not totally block electron flow in Neurospora mitochondria [Lambowitz et al., 1972] and therefore a very low import can occur.) Mitochondria were re-isolated, resuspended in fresh lysate with unlabeled precursors, and mixed with KCN/oligomycin (reactions 2,4 , and 6) or valinomycin (reaction 7). Reactions 1 to 4 were kept on ice to preserve the initial situation; reactions 5 to 7 were first incubated for $10 \mathrm{~min}$ at $11^{\circ} \mathrm{C}$ and then shifted to $25^{\circ} \mathrm{C}$ to allow further reaction. One-half of each reaction was treated with proteinase $K$ to test for fully imported $F_{1} \beta$. Ir respective of the presence (reaction 5) or absence of a membrane potential (reactions 6 and 7), during the second incubation a considerable amount of protease sensitive $F_{1} \beta$ (cf. reaction 3 ) became protease resistant. A quantitative evaluation of a similar experiment is given in Figure 7B. Here, the membrane potential was dissipated with antimycin plus oligomycin. In summary, these data show that the transmembrane forms of pre- $F_{1} \beta$ and $m-F_{1} \beta$ are indeed intermediates on the assembly pathway; there is no requirement for a membrane potential to complete the translocation of the $F_{1} \beta$ polypeptide chain, once the amino-terminal section has been transferred across the membrane in a potential-dependent manner.

\section{Intermediate Sized Cytochrome $c_{1}$ That Accumulates} In Vivo at $7^{\circ} \mathrm{C}$ is a Translocational Intermediate Neurospora cells were labeled with $\left({ }^{3} \mathrm{H}\right)$ leucine either for $7 \mathrm{~min}$ at $7^{\circ} \mathrm{C}$ or for $60 \mathrm{~min}$ at $25^{\circ} \mathrm{C}$. Mitochondria isolated from the hyphae labeled at $7^{\circ} \mathrm{C}$ had mainly $\mathrm{i}-\mathrm{c}_{1}$, whereas at $25^{\circ} \mathrm{C}$ exclusively the $m-c_{1}$ was found. Most of the $m-c_{1}$ was resistant to proteinase $K$, whereas the majority of the $7^{\circ} \mathrm{C} i-c_{1}$ was digested by very low concentrations of added trypsin (Figure 8A). Control of cytochrome $c$ accessibility to the respiratory chain showed that these mitochondria were at least $85 \%$ intact. Mitochondria isolated from cells labeled at $7^{\circ} \mathrm{C}$ were incubated in $0.3 \mathrm{M}$ sucrose, $60 \mathrm{mM}$ $\mathrm{KCl}, 2 \mathrm{mM} \mathrm{NADH}, 10 \mathrm{mM}$ Tris- $\mathrm{HCl}\left(\mathrm{pH} \mathrm{7.5)}\right.$ at $25^{\circ} \mathrm{C}$ or at $0^{\circ} \mathrm{C}$. At $25^{\circ} \mathrm{C}$ the $\mathrm{i}-\mathrm{c}_{1}$ was converted to $\mathrm{m}-\mathrm{c}_{1}$ (Figure $8 \mathrm{~B}$ ). At the same time it acquired protease resistance (not shown). The processing in vitro of the protease sensitive $\mathrm{i}-\mathrm{c}_{1}$ to protease resistant $\mathrm{m}-\mathrm{c}_{1}$ did not require a membrane potential (Figure $8 \mathrm{C}$ ). Recovery of the label originally present in $\mathrm{i}-\mathrm{c}_{1}$, in the form of $\mathrm{m}-\mathrm{c}_{1}$, after incubation of mitochondria was not complete and somewhat variable; we attribute this to the action of contaminating proteases in the mitochondrial preparation which attack the rather sensitive intermediate. From these observations we conclude 

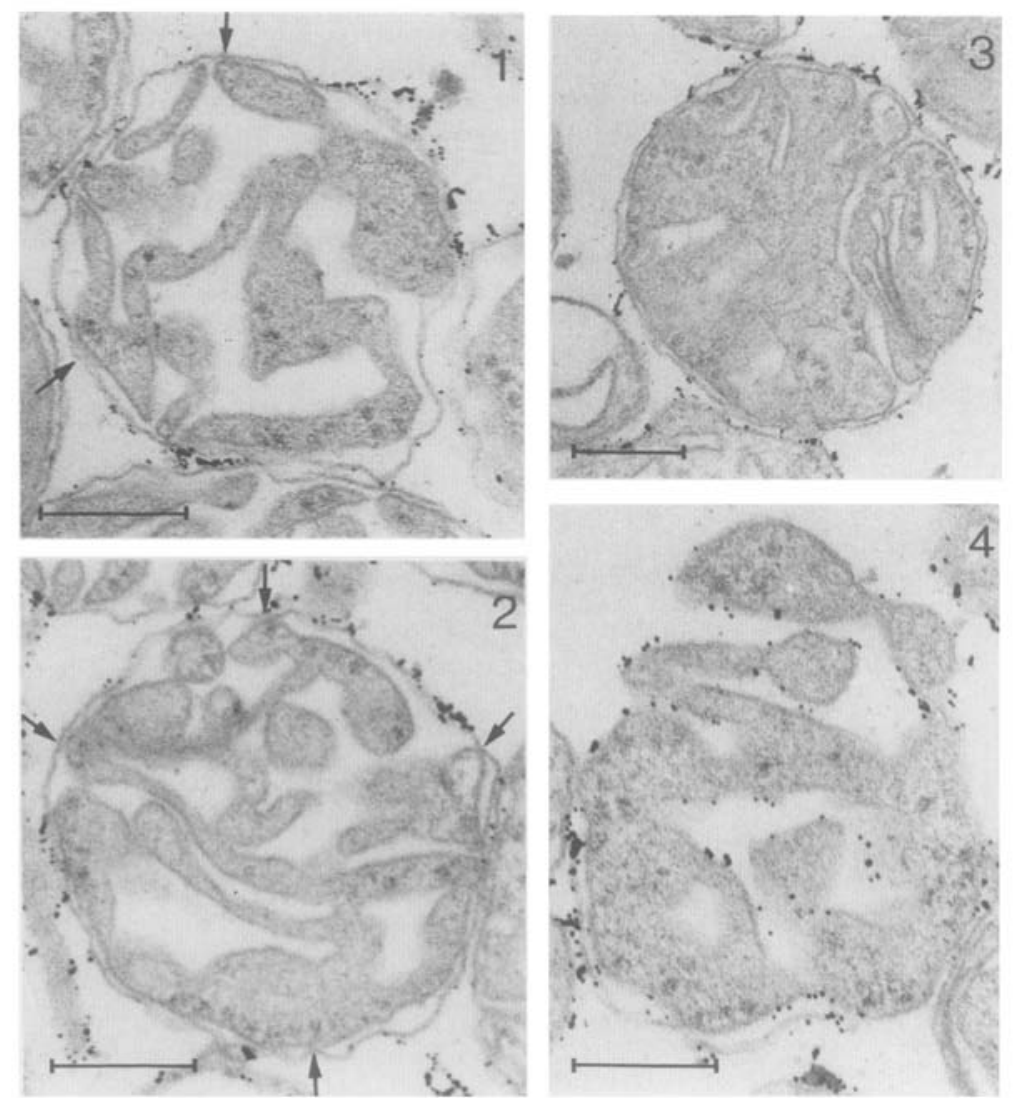

Figure 5. Accessibility of the Mitochondrial Intermembrane Space to Colloidal Gold Particles

Mitochondria were isolated in $0.3 \mathrm{M}$ sucrose, 1 mM EDTA, $10 \mathrm{mM}$ MOPS (pH 7.5). They were resuspended in $0.3 \mathrm{M}$ sucrose, $10 \mathrm{mM}$ MOPS (pH 7.5). A suspension of colloidal goid particles (diameter $4.5-5.5 \mathrm{~nm}$ ) in the same buffer was added. Gold particles were prepared by reduction of $\mathrm{AuCl}_{4}$ with white phosphorous according to the procedure of Frens (1973). After incubation for $30 \mathrm{~min}$ at $0^{\circ} \mathrm{C}$ the mitochondria were pelleted again, fixed with $2 \%$ glutaraldehyde, and treated with $\mathrm{OsO}_{4}$, uranyl acetate, and lead citrate as described (Desel et al., 1982). Epon sections were viewed in a Siemens Elmiscop 102.

Selected images of mitochondria with intact outer membrane (1-3) and of a mitochondrion with damaged outer membrane (4) are shown. Arrows point to regions at which outer and inner membranes are in close proximity. Bar represents $0.2 \mu \mathrm{m}$. that a translocational intermediate can be accumulated in vivo and that the protease sensitivity of the $i-c_{1}$ seen in vitro is not caused by the incubation in the reticulacyte lysate.

\section{Precursors of $F_{1} \beta$ and Cytochrome $c_{1}$ Bound to Antibodies Are Processed by Mitochondria}

The experiments described suggested that precursor proteins are processed by the processing peptidase in the matrix even if a large region of the molecule is still outside the outer membrane. We then tested whether a similar situation could be generated by a different approach, namely by binding precursors to their corresponding antibodies before importing them into mitochondria. As the antibodies had been prepared against the mature proteins, relatively little interference with the amino-terminal extensions of the precursor proteins was expected. On the other hand it seemed unlikely that mitochondria would be able to import a precursor-antibody complex completely into the matrix space.

A reticulocyte lysate containing labeled precursors was incubated with control serum or with antisera against either $F_{1} \beta$ or cytochrome $c_{1}$. Mitochondria were then added and transfer was performed under control conditions. From the mitochondria of the incubations that had received control serum, $F_{1} \beta$ and $c_{1}$ were immunoprecipitated by adding the respective antisera. For immunoprecipitation from mitochondria of those incubations that had received antisera, no further antisera were added. All immunocomplexes were harvested with protein A-Sepha-

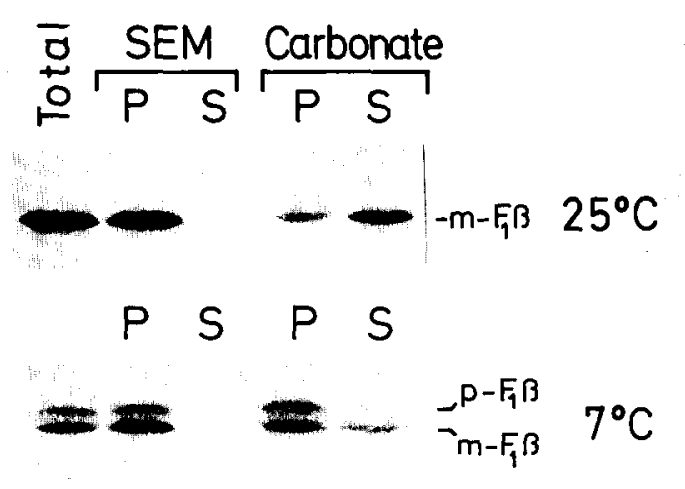

\section{$\begin{array}{lllll}1 & 2 & 3 & 4 & 5\end{array}$}

Figure 6. $F_{1} \beta$ Imported at Low Temperature is Mainly Located in the Mitochondrial Mernbrane Fraction

Transfer of precursors was allowed to take place at $7^{\circ} \mathrm{C}$ and $25^{\circ} \mathrm{C}$ for 30 min (see legend to Figure 1). Then mitochondria were re-isolated. From one half $F, \beta$ was immunoprecipitated (lanes 1 ). The other half was resuspended in $1 \mathrm{ml}$ SEM $(0.3 \mathrm{M}$ sucrose, $2 \mathrm{mM}$ EDTA, and $10 \mathrm{mM}$ MOPS, pH 7.3; lanes 2 and 3) or in $1 \mathrm{ml} 0.1 \mathrm{M} \mathrm{Na}_{2} \mathrm{CO}_{3}$ (lanes 4 and 5). After $15 \mathrm{~min}$ incubation at $0^{\circ} \mathrm{C}$ the samples were transferred to new Eppendorf cups and centrifuged for $60 \mathrm{~min}$ at $200,000 \times \mathrm{g}$. The pellets were dissociated in $20 \mu \mathrm{l} 2 \%$ SDS, $60 \mathrm{mM}$ Tris- $\mathrm{HCl}(\mathrm{pH} \mathrm{6.8),} \mathrm{10 \%}$ glycerol and kept on ice. The supernatants were made $0.15 \%$ in deoxycholate, $0.1 \%$ in bovine serum albumin, and $10 \%$ in trichloroacetic acid, and were incubated for $10 \mathrm{~min}$ at $56^{\circ} \mathrm{C}$. Precipitated protein was recovered by centrifugation for $10 \mathrm{~min}$ at $39,000 \times \mathrm{g}$. The pellets were dissolved in $20 \mu \mathrm{l}$ SDS-containing buffer. All samples were then kept for $3 \mathrm{~min}$ at $95^{\circ} \mathrm{C}$ and $0.5 \mathrm{ml}$ Triton-containing buffer was added. $\mathrm{F}_{1} \beta$ was immunoprecipitated and subjected to electrophoresis and fluorography as described. $P$, pellet; $S$, supernatant. 

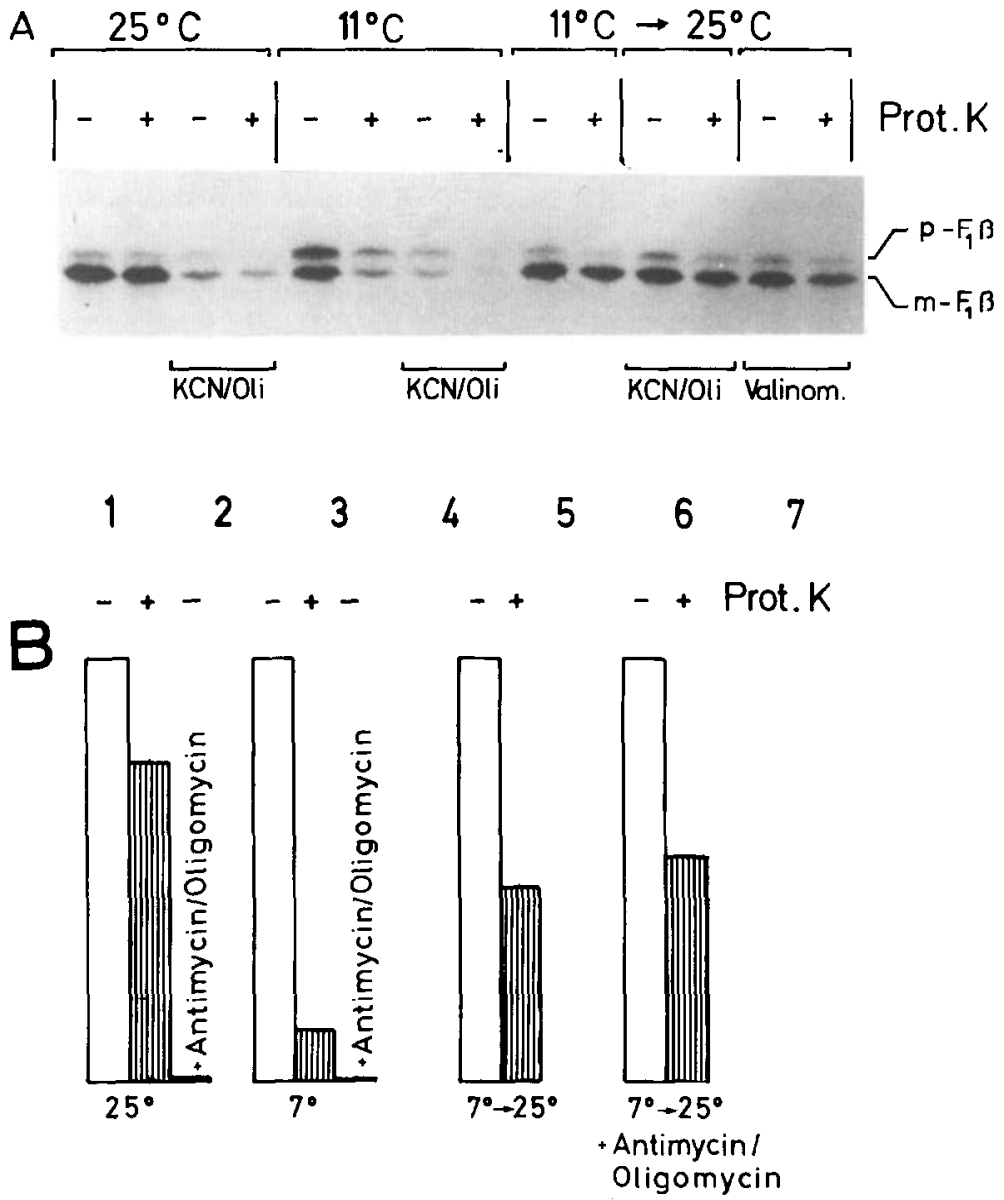

Figure 7. Protease Sensitive $F_{1} \beta$ Accumulated at Low Temperature Can Be Chased into Protease Protected $F_{1} \beta$ at $25^{\circ} \mathrm{C}$ in the Absence of a Membrane Potential

(A) Mitochondria were incubated in the supplemented postribosomal supernatant in the presence (reactions 2 and 4) or absence of 1 $\mathrm{mM} \mathrm{KCN} / 10 \mu \mathrm{M}$ oligomycin (reactions $1,3,5,6$, 7). After $30 \mathrm{~min}$ at $25^{\circ} \mathrm{C}$ (reactions 1 and 2) or $11^{\circ} \mathrm{C}$ (reactions 3 to 7 ) the mitochondria were reisolated and resuspended in ice-cold supplemented postribosomal supernatant, to which had been added KCN/oligomycin (reactions 2,4 , and 6) or $0.1 \mu \mathrm{M}$ valinomycin (reaction 7). Reactions 1 to 4 were kept on ice. Reactions 5, 6, and 7 were incubated for $20 \mathrm{~min}$ at $25^{\circ} \mathrm{C}$. After incubation for $5 \mathrm{~min}$ on ice, to onehalf of each sample $5 \mu \mathrm{g} / \mathrm{ml}$ proteinase $\mathrm{K}$ was added. All samples were kept at $0^{\circ} \mathrm{C}$ for $20 \mathrm{~min}$, then $1 \mathrm{mM}$ PMSF was added. Mitochondria were re-isolated and $F_{1} \beta$ was immunoprecipitated.

(B) Quantitative evaluation of chasing protease sensitive $m-F_{1} \beta$ accumulated at $7^{\circ} \mathrm{C}$ to protease resistant $m-F_{1} \beta$. The values are the means of three separate experiments. Experimental conditions were as described in (A) with the exception that $4 \mu \mathrm{M}$ antimycin $A$ instead of KCN was used to block electron transport. rose. Energy-dependent processing of pre- $F_{1} \beta$ to $m-F_{1} \beta$ occurred whether or not specific antibodies were present (Figure 9A, lanes 1 and 2). However, pre- $c_{1}$ was processed to $i-c_{1}$ in the sample containing cytochrome $c_{1}$ antiserum, rather than to $m-c_{1}$ which was produced in the control (Figure 9B, lanes 1). Proof for the notion that antibody bound precursor was processed comes from an immunocompetition experiment. When import was carried out in the absence of specific antibodies, immunoprecipitation of labeled imported $F_{1} \beta$ or cytochrome $c_{1}$ was dependent on the addition of specific antibodies (not shown) and was prevented by addition of an excess of mitochondria; when the reticulocyte lysate was preincubated with specific antibodies, however, virtually the same amount of labeled $m-F_{1} \beta$ or $i-c_{1}$ was found even after addition of excess mitochondria (lanes 3 ). This shows that the processed precursors were indeed bound to the antibody so that addition of excess antigen did not lead to immunocompetition. The antibody-linked processed species were sensitive to added protease, in contrast to the $F_{1} \beta$ and cytochrome $c_{1}$ transferred in the presence of control serum (lanes 4). This excludes the possibility that the precursor-antibody complexes were completely translocated into the mitochondria. When the protease treated samples from the incubations in the presence of specific antibodies were lysed with SDS and then incubated with sufficient antibodies to bind all $F_{1} \beta$ or cytochrome $c_{1}$ present in these mitochondria, a considerable amount of $m-F_{1} \beta$ and some m-c $c_{1}$ was found in the immunoprecipitate (lanes 5). Apparently, the preincubation with the antibody did not lead to a complete block of normal import. It remains to be determined whether part of pre- $F_{1} \beta$ does not react with antibody or whether the $F_{1} \beta$ in the antibody complex is slowly transferred further.

It should be noted that with other precursor proteins, e.g. subunit 9 of $F_{0} F_{1}-A T P a s e$ or the $\mathrm{Fe} / \mathrm{S}$ protein of respiratory complex III, binding of antibodies did inhibit uptake and processing by mitochondria (Schmidt and Neupert, unpublished results). The antibody to subunit 9 even blocked processing by the isolated enzyme of the intermediate sized to the mature form, but not of the precursor form to the intermediate (Schmidt et al., 1984). This suggests that in the case of subunit 9 the antibodies bind in such a manner to the precursor protein that the translocation of the amino-terminal presequence across the mitochondrial membranes is inhibited.

\section{Discussion}

The interpretation of the experiments presented in this report is summarized in Figure 10. We suggest that at low temperature a small amino-terminal section of the $F_{1} \beta$ precursor can be translocated across both outer and inner membranes (Figure 10A). This reaction requires a membrane potential. The presequence is then cleaved by the processing peptidase in the matrix. Further translocation 

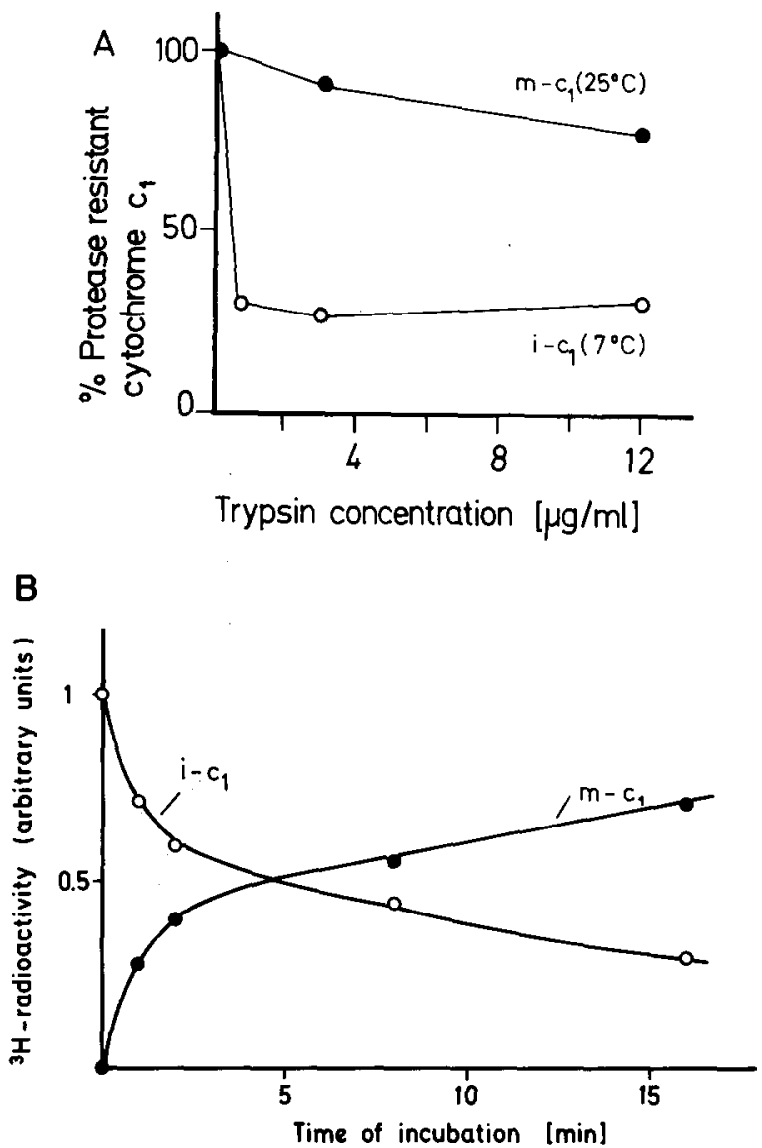

C

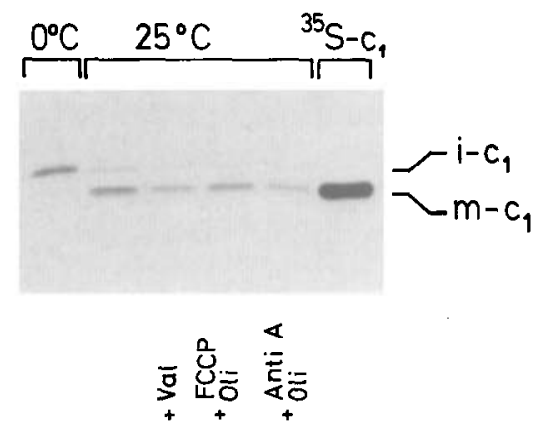

\section{$123 \quad 4 \quad 56$}

Figure 8. A Protease Sensitive Intermediate of Cytochrome $c_{1}$ Accumulates at $7^{\circ} \mathrm{C}$ in Intact Neurospora Cells

Neurospora cultures $(100 \mathrm{ml}, 0.6 \mathrm{~g}$ wel weight of hyphae) were labeled either at $25^{\circ} \mathrm{C}$ for $60 \mathrm{~min}$ or at $7^{\circ} \mathrm{C}$ for $7 \mathrm{~min}$ with $1 \mathrm{mCi}\left({ }^{3} \mathrm{H}\right.$ )leucine (specific radioactivity $50 \mathrm{Ci} / \mathrm{mmole}$, Amersham Buchler). The hyphae were harvested at $0^{\circ} \mathrm{C}$ on an ice cooled funnel. After grinding with sand, mitochondria were isolated by differential centrifugation.

(A) Trypsin treatment of mitochondria isolated from cells labeled at $25^{\circ} \mathrm{C}$ and $7^{\circ} \mathrm{C}$, respectively. After immunoprecipitation, gel electrophoresis, and fluorography, intermediate sized and mature cytochrome $c_{1}$ were quantitated by densitometry.

(B) In vitro conversion of intermediate sized cytochrome $c_{1}$ accumulated at $7^{\circ} \mathrm{C}$ in vivo. Mitochondria were resuspended in $0.3 \mathrm{M}$ sucrose, $60 \mathrm{mM} \mathrm{KCl}, 10 \mathrm{mM} \mathrm{Trls}-\mathrm{HCl}(\mathrm{pH} 7.5)$, and $2 \mathrm{mM} \mathrm{NADH}$. Samples of $70 \mu$ containing $30 \mu \mathrm{g}$ of mitochondria were incubated at $25^{\circ} \mathrm{C}$ for the indicated time periods. Mitochondria were re-isolated by centrifugation, dissolved in SDS-containing buffer (see Figure 6), and kept for 5 min at $95^{\circ} \mathrm{C}$. Then $0.5 \mathrm{ml} 0.3 \mathrm{M} \mathrm{NaCl}, 1 \%$ Triton X-100 was added and cytochrome $c$, immunoprecipitated. A fluorograph of the gel was analyzed by densitometry.
A

a)

Control serum

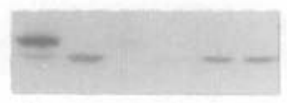

$=\begin{aligned} & p-F_{1} B \\ & m-F_{1} B\end{aligned}$

$0 \begin{array}{llllll}0 & 1 & 2 & 3 & 4 & 5\end{array}$

b)

Anti-F $F_{1} \beta$ serum

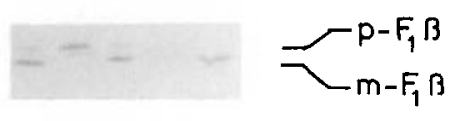

$\begin{array}{lllll}1 & 2 & 3 & 4 & 5\end{array}$

$B$

a)

Control serum

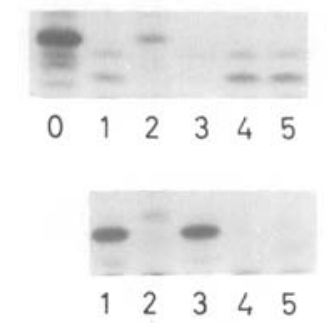

b)

Anti- $c_{1}$ serum

$$
\begin{array}{lllll}
1 & 2 & 3 & 4 & 5
\end{array}
$$

Figure 9. Binding of Precursors of $F \beta$ and Cytochrome $c$, to Their Antibodies Does Not Prevent Transfer into Intermediate Location

To four $250 \mu$ samples of supplemented postribosomal supernatant of a reticulocyte lysate containing labeled precursor proteins was added either $10 \mu \mathrm{l}$ control serum (two samples), $10 \mu \mathrm{l}$ anti-F $\beta$ serum, or $10 \mu \mathrm{l}$ anti-cytochrome $c_{1}$ serum. The samples were incubated for $30 \mathrm{~min}$ at $25^{\circ} \mathrm{C}$ and each then divided into five reactions. Reactions number 2 received $4 \mu \mathrm{M}$ antimycin $\mathrm{A} / 10 \mu \mathrm{M}$ oligomycin. Mitochondria were added to all reactions (final concentration $0.2 \mathrm{mg}$ protein/ml) and incubation continued for another $30 \mathrm{~min}$ at $25^{\circ} \mathrm{C}$. They were then cooled to $0^{\circ} \mathrm{C}$ and reactions 4 and 5 were treated with $5 \mu \mathrm{g} / \mathrm{ml}$ proteinase $\mathrm{K}$ as described. After adding $1 \mathrm{mM}$ PMSF to all reactions, mitochondria were re-isolated. To reactions 3,20 times the amount of freshly isolated mitochondria was added. The other reactions received the same volume SET. Mitochondria of reactions 1 to 4 were lysed with Tritoncontaining buffer, those of reactions 5 in SDS-containing buffer and diluted with Triton-containing buffer (see Figure 8). After a clarifying spin the respective antibodies and protein A-Sepharose were added to the control samples and to reactions 5 of the antibody preincubated samples. To the other samples only protein A-Sepharose was added. All were mixed for $1 \mathrm{hr}$ at $4^{\circ} \mathrm{C}$ and the immunoprecipitates were washed, dissociated, and analyzed as described. An immunoprecipitate of the supernatant of reaction 1 containing precursor to $F_{1} \beta$ or cytochrome $c_{1}$ was run to the left of reaction 1 (lanes 0 ).

(A) Immunoprecipitation of $F_{1} \beta$; (B) Immunoprecipitation of cytochrome $c_{1}$. (a) Incubation of reticulocyte lysate with control serum; (b) incubation of reticulocyte lysate with antiserum against $F_{1} \beta$ and cytochrome $c_{1}$, respectively.

(C) Conversion of the $7^{\circ} \mathrm{C}$ in vivo intermediate to mature sized cytochrome $c_{1}$ does not depend on a membrane potential. ${ }^{3} \mathrm{H}$-labeled intermediate sized cytochrome $c_{1}$ was accumulated, and mitochondria were isolated and resuspended as in (B). One aliquot was kept at $0^{\circ} \mathrm{C}$ (lane 1); four other aliquots were incubated at $25^{\circ} \mathrm{C}$ for $30 \mathrm{~min}$ (lanes 2-5). One served as a control (lane 2); the others received $0.4 \mu \mathrm{M}$ valinomycin (lane 3); $2 \mu \mathrm{M}$ carbonylcyanide-4-trifluoromethoxyphenylhydrazone (FCCP) $/ 10 \mu \mathrm{M}$ oligomycin (lane 4); or $4 \mu \mathrm{M}$ antimycin $/ 10 \mu \mathrm{M}$ oligomycin (lane 5). After incubation, mitochondria were harvested and cytochrome $c_{1}$ immunoprecipitated as in (B). Lane 6 shows cytochrome $c_{1}$ immunoprecipitated from mitochondria of cells metabolically labeled with ${ }^{\left({ }^{35}\right.}$ ) sulfate (Teintze et al., 1982). 
A
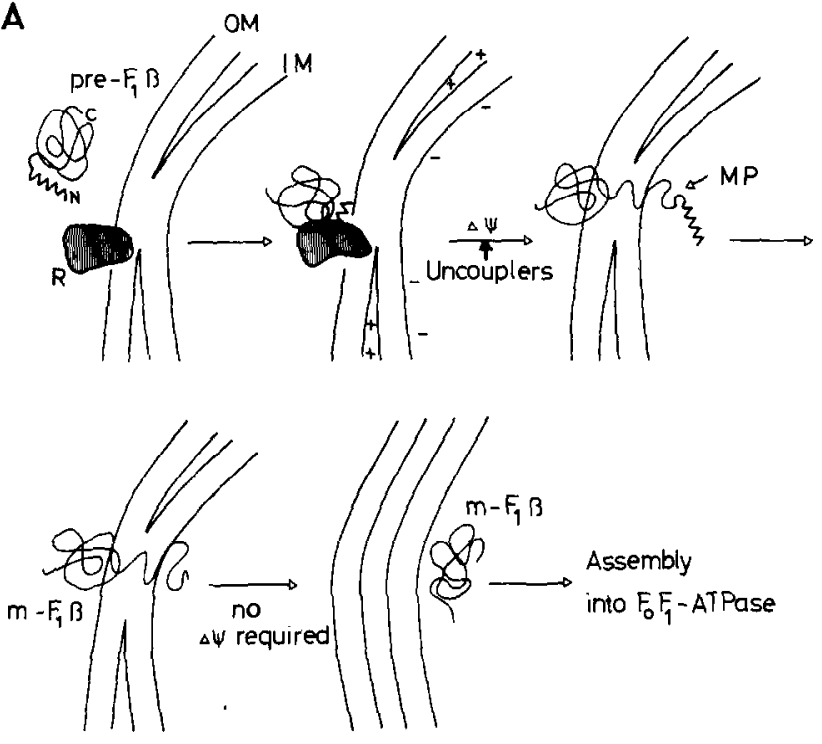

B
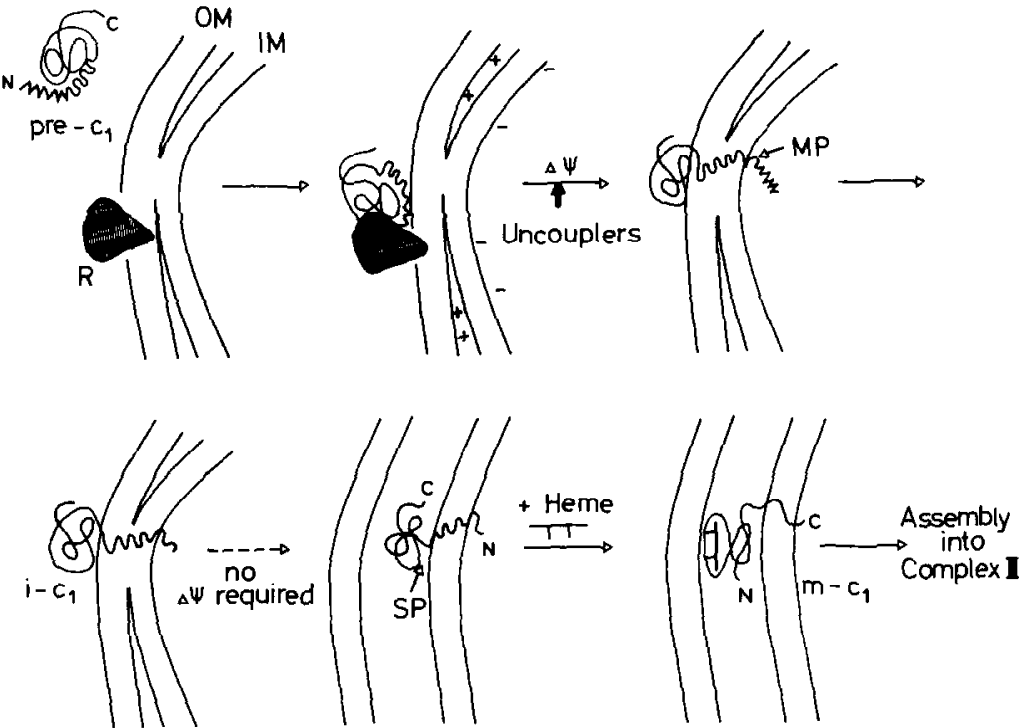

Figure 10. Model of Translocation of Precursors across Mitochondrial Membranes

(A) Translocation of $\mathrm{F}_{1} \beta$; (B) Translocation of cytochrome $\mathrm{c}_{1}$. OM, IM, outer and inner mitochondrial membrane; MP, matrix metallo processing peptidase; SP, second protease involved in cytochrome $c$, processing; $R$, receptor; pre- $F_{1} \beta$ and pre- $c_{1}$, precursors to $F_{1} \beta$ and cytochrome $c_{1} ; m-F_{1} \beta$ and $m-c_{1}$, mature-sized $F_{1} \beta$ and cytochrome $c_{1} ; i-c_{1}$, intermediate-sized cytochrome $c_{1} ; \Delta \psi$, mitochondrial membrane potential; N, amino terminus; C, carboxy terminus. of the polypeptide occurs only slowly at low temperature. The lipid phase under these conditions is probably too rigid to be overcome by the large region of folded precursor still located outside the outer membrane. When the temperature is raised, however, to $25^{\circ} \mathrm{C}$, translocation into the matrix space is completed and the mature $F_{1} \beta$ is no longer sensitive to added protease. This transmembrane transfer of the major carboxy-terminal portion is not dependent on the membrane potential. In the case of cytochrome $c_{1}$ (Figure 10B), at low temperature the part of the molecule that crosses outer and inner membranes may consist at least partially of the additional hydrophobic segment, which follows the prepiece cleaved by the matrix processing peptidase (Sadler et al., 1984). This second prepiece is believed to be removed later in the assembly pathway by an unrelated peptidase located at the surface of the inner membrane (Ohashi et al., 1982; Teintze et al., 1982; see also model for cytochrome c peroxidase assem- bly, Kaput et al., 1982). According to the assembly mechanism proposed here the bulk of the intermediate form of cytochrome $c_{1}$ is trapped outside the outer membrane at low temperature. When the temperature is raised, the intermediate will move completely across the outer membrane into the intermembrane space. This would explain the observation of both a protease accessible and a protease inaccessible form of intermediate cytochrome $c_{1}$ in intact mitochondria. Then the heme group may be added, the amino-terminal piece removed, and the mature sized cytochrome $c_{1}$ will be anchored with its carboxy terminus in the inner membrane (Wakabayashi et al., 1980). It should, however, be stressed that this is only one possible model for the assembly pathway and other possibilities exist. In particular, complete translocation of the low temperature intermediate into the matrix may occur, followed by translocation back into the intermembrane space.

The observation that precursors bound to antibody can 
be partially translocated such that the amino-terminal presequence can be removed provides strong independent evidence for this interpretation. It is, however, not known whether this leads to the trapping of exactly the same kind of intermediates as lowering the temperature during import.

The following new details about the mechanism of protein transport into mitochondria can be deduced from these findings. First, the $F_{1} \beta$ and cytochrome $c_{1}$ precursors appear to enter the matrix initially with the amino-terminal piece, which contains the hydrophilic and positively charged extra polypeptide (Sadler et al., 1984; Takeda and Douglas, 1985). This reaction is dependent on the membrane potential. Therefore the potential seems to be required for the translocation of the positively charged presequence. Independent evidence suggests that the $\Delta \psi$ component of $\Delta \mu \mathrm{H}^{+}$but not $\Delta \mathrm{pH}$ is important for translocation (Pfanner and Neupert, unpublished). Thus, the role of the membrane potential may be an electrophoretic effect on the positively charged additional sequences.

Second, the data presented strongly indicate the existence of "translocation contact sites" between outer and inner mitochondrial membranes. The experiments show that the translocational intermediate accumulating at low temperature becomes processed at the amino terminus, whereas the major part of the molecule is still accessible to added protease or bound to antibody. This indicates a transmembrane arrangement of the intermediate, and implies that the polypeptide simultaneously spans both outer and inner membranes. This is the first experimental evidence for the involvement of such translocation contact sites, although they have been repeatedly suggested in models for protein transport into mitochondria (Schatz and Butow, 1983; Zwizinski et al., 1983; Hay et al., 1984; Harmey and Neupert, 1985). Fusion sites or contact sites have been described at the electron microscopic level (Hackenbrock, 1968; Van Venetie and Verkleij, 1982). These morphologically defined approximations of the two membranes may or may not be related to the functionally defined sites described here. Kellems et al. (1975) have observed the binding of cytoplasmic ribosomes to such approximations in yeast mitochondria, and have suggested that these are involved in the transport of proteins. On the other hand, evidence for association of cytoplasmic ribosomes which translate mitochondrial proteins with mitochondria has been provided (Ades and Butow, 1980; Suissa and Schatz, 1982). These data and our findings taken together imply that at least some precursors may be translocated into mitochondria in a "cotranslational" fashion. It should, however, be stressed that there is clearly no obligatory coupling of translation and translocation.

Third, our data bear relevance to the unsolved problem of how large proteins can cross biological membranes. The major section of the $F_{1} \beta$ can be translocated across both membranes (or intermediate cytochrome $c_{1}$ at least across the outer membrane) without the need of a membrane potential. This indicates that the membrane potential is required for allowing the passage of the amino-terminal part and that this is sufficient to trigger the transmembrane movement of a large polypeptide chain. These conclusions seem compatible with studies on a fusion protein between the presequence of yeast cytochrome oxidase subunit IV and a mouse cytosolic protein, dihydrofolate reductase, which demonstrated that the presequence can trigger the transmembrane movement of the cytosolic protein (Hurt et al., 1984a; 1984b). It may be argued that translocation of the amino-terminal part can occur even at lower temperature since the membrane potential helps to overcome the barrier posed by the membrane lipid structure. The successive translocation of the major part of the molecule may then be hindered by the rigid lipid structure at lower temperature. It remains to be determined whether these steps in the transport pathway are common to many of the imported precursor proteins.

The data presented here are consistent with a model of protein transmembrane movement in which separate domain-like structures of the folded precursor polypeptide chain are translocated. This is similar to the mode suggested for the movement of secreted polypeptides across the E. coli plasma membrane (Randall, 1983). Thus, transmembrane movement of proteins across prokaryotic and mitochondrial membranes may share some basic features.

\section{Experimental Procedures}

\section{Isolation of Mitochondria}

Neurospora crassa wild-type $74 \mathrm{~A}$ was grown as described (Teintze et al., 1982). Hyphae were harvested by filtration. All following procedures were carried out at $0^{\circ} \mathrm{C}$ to $4^{\circ} \mathrm{C}$. One gram of hyphae was ground with $1 \mathrm{~g}$ quartz sand and $1 \mathrm{ml}$ of SET medium $(0.3 \mathrm{M}$ sucrose, $1 \mathrm{mM}$ EDTA, $30 \mathrm{mM}$ Tris- $\mathrm{HCl}, \mathrm{pH} 7.4$ ) in a mortar for $1 \mathrm{~min}$. The slurry was diluted by addition of $5 \mathrm{ml} \mathrm{SET}$ medium and the mitochondria were isolated by differential centrifugation (Sebald et al., 1979). For storage, samples of $20 \mu \mathrm{l}$ in Eppendorf cups were shock-frozen in liquid nitrogen and kept at $-80^{\circ} \mathrm{C}$. They were thawed by incubation for $1 \mathrm{~min}$ at $25^{\circ} \mathrm{C}$. In some experiments mitochondria were further purified by centrifugation in Percoll (Pharmacia). Three hundred microliters of $22 \%$ Percoll in SET were layered over $40 \mu \mathrm{l}$ of $40 \%$ Percoll in SET in Sarstedt $72 / 702$ microfuge tubes, then a mitochondrial suspension $(0.5$ $\mathrm{mg}$ protein in $50 \mu \mathrm{S}$ SET) was applied to the top and the sample centrifuged for $10 \mathrm{~min}$ at $39,000 \times \mathrm{g}$. The mitochondria formed two bands; the lower one was collected and diluted with SET to $1 \mathrm{ml}$, pelleted by centrifugation for $5 \mathrm{~min}$ at $27,000 \times \mathrm{g}$, and resuspended in SET to a protein concentration of 1 to $5 \mathrm{mg} / \mathrm{ml}$. The mitochondria were then used for in vitro import studies either directly or after storage.

\section{Binding and Import of Precursors Synthesized in} Reticulocyte Lysates

Neurospora proteins were synthesized in rabbit reticulocyte lysates in the presence of $\left({ }^{35} \mathrm{~S}\right.$ )methionine (specific radioactivity $500 \mathrm{Ci} / \mathrm{mmole}$, Amersham Buchler) (Pelham and Jackson, 1976). Postribosomal supernatants were prepared and supplemented as described (Zimmermann and Neupert, 1980). Dithiothreitol, glutathione, and NADH were added to concentrations of 1,5 , and $5 \mathrm{mM}$, respectively, from $100 \mathrm{x}$ concentrated stock solutions. This mixture was stored at $-80^{\circ} \mathrm{C}$ in aliquots. Samples were thawed by incubation at $25^{\circ} \mathrm{C}$ for $2 \mathrm{~min}$. Routinely, a combination of oligomycin and antimycin $\mathrm{A}(10 \mu \mathrm{M}$ and $4 \mu \mathrm{M}$ final concentrations, added from 100 -fold concentrated stock solutions in ethanol) was used to prevent import of precursors (Schleyer et al., 1982). All reactions were made chemically identical by adding the same volumes of inhibitor-free solutions to the respective control samples. Binding and import were initiated by addition of isolated mitochondria to a concentration of $0.2 \mathrm{mg}$ protein per $\mathrm{ml}$ and incubation at $25^{\circ} \mathrm{C}$ or the temperatures indicated in the text. The samples were then incubated for $\mathbf{1 5} \mathrm{min}$ in an ice-water bath and SET or pro- 
teinase $K$ in SET added to the concentrations indicated. After 20 to 30 min PMSF ( $1 \mathrm{mM}$ final concentration) was added to all samples.

\section{Immunoprecipitation}

The samples were transferred into new Eppendorf cups, mitochondria reisolated by centrifugation for $5 \mathrm{~min}$ at $27,000 \times \mathrm{g}$ at $2^{\circ} \mathrm{C}$, solubilized with Triton X-100-containing buffer (Zimmermann and Neupert, 1980), and the mixture freed from insoluble material by centrifugation for 5 min at $39,000 \times \mathrm{g}$. When indicated the mitochondria were dissolved in SDS-containing buffer as described (Schleyer et al., 1982). PMSF was always added to a concentration of $1 \mathrm{mM}$. Sufficient amounts of antisera against cytochrome $c_{1}$ or $\beta$-subunit of $F_{-}$-ATPase and protein A-Sepharose (Pharmacia) were added and mixed for at least $1 \mathrm{hr}$ at $4^{\circ} \mathrm{C}$. The beads were then washed and dissociated as described (Schleyer et al., 1982).

Determination of Intactness of the Outer Mitochondrial Membrane Succinate:cytochrome c-oxidoreductase activity was determined essentially following the procedure of Douce et al. (1973). The reaction mixture contained in $0.5 \mathrm{ml} 5 \mathrm{mM} \mathrm{MgCl}, 10 \mathrm{mM} \mathrm{KCl}, 10 \mathrm{mM} \mathrm{K}_{2} \mathrm{HPO}_{4^{-}}$ $\mathrm{HCl}(\mathrm{pH} 7.2), 50 \mu \mathrm{M} \mathrm{KCN}, 0.2 \mathrm{mM}$ ATP, $20 \mathrm{mM}$ sodium succinate $(\mathrm{pH}$ 7.0), and $50 \mu \mathrm{M}$ cytochrome c (from horse heart, type III, Sigma, St Louis) and sucrose at concentrations between $0 \mathrm{mM}$ and $300 \mathrm{mM}$. Mitochondria were mixed in and the reaction was followed at $25^{\circ} \mathrm{C}$ by recording the absorbance at $550 \mathrm{~nm}$.

\section{Miscellaneous}

Mitochondrial protein was determined by the method of Bradford (1976), SDS-polyacrylamide gel electrophoresis was carried out according to Lämmli (1970) and fluorography as described by Chamberlain (1979). The films (Kodak X-Omat AR) were preflashed (Laskey, 1980)

\section{Acknowledgments}

We thank Dr. V. Herzog for preparing electron micrographs and for performing the experiments on the permeability of mitochondrial membranes to gold particles. We appreciate greatly the gifts of antibodies against $F_{1} \beta$ and cytochrome $c_{1}$ by Dr. W. Sebald, Stöckheim and Dr. $H$. WeiB, Düsseldorf. We are grateful to Christine Wagenpfeil for excellen technical assistance. This work was supported by the Deutsche Forschungsgemeinschaft (grant $\mathrm{Ne}$ 101/19-1) and by the Fonds de Chemischen Industrie.

The costs of publication of this article were defrayed in part by the payment of page charges. This article must therefore be hereby marked "advertisement" in accordance with 18 U.S.C. Section 1734 solely to indicate this fact.

Received May 30, 1985; revised July 29, 1985

\section{References}

Ades, I. Z., and Butow, R. A. (1980). The products of mitochondriabound cytoplasmic polysomes in yeast. J. Biol. Chem. 255, 9918-9935. Böhni, P., Gasser, S., Leaver, C., and Schatz, G. (1980). A matrixlocalized mitochondrial protease processing cytoplasmically-made precursors to mitochondrial proteins. In The Organization and Expression of the Mitochondrial Genome, A. M. Kroon and C. Saccone, eds. (Amsterdam: Elsevier/North-Holland), pp. 432-433.

Bradford, M. M. (1976). A rapid and sensitive method for the quantitation of microgram quantities of protein utilizing the principle of proteindye binding. Anal. Biochem. 72, 248-254.

Chamberlain, J. P. (1979). Fluorographic detection of radioactivity in polyacrylamide gels with the water-soluble fluor, sodium salicylate. Anal. Biochem. 98, 132-135.

Conboy, J. G., Fenton, W. A., and Rosenberg, L. E. (1982). Processing of pre-ornithine transcarbamylase requires a zinc-dependent protease localized to the mitochondrial matrix. Biochem. Biophys. Res. Com mun. 105, 1-7.

Desel, H., Zimmermann, R., Janes, M., Miller, F., and Neupert, W. (1982). Biosynthesis of glyoxysomal enzymes In Neurospora crassa. Ann. N. Y. Acad. Sci. 386, 377-390
Douce, R., Mannella, C. A., and Bonner, W. D. Jr. (1973). The external NADH dehydrogenases of intact plant mitochondria. Biochim. Biophys. Acta 292, 105-116.

Frens, G. (1973). Controlled nucleation for the regulation of the particle size in monodisperse gold suspensions. Nat. Phys. Sci. 241, 20-22. Fujiki, Y., Hubbard, A. L., Fowler, S., and Lazarow, P. B. (1982). Isolation of intracellular membranes by means of sodium carbonate treatment application to endoplasmic reticulum. J. Cell Biol. 93, 97-102.

Gasser, S. M., Daum, G., and Schatz, G. (1982a). Import of proteins into mitochondria. Energy-dependent uptake of precursors by isolated mitochondria. J. Biol. Chem. 257, 13,034-13,041.

Gasser, S. M., Ohashi, A., Daum, G., Boehni, P. C., Gibson, J., Reid, G. A., Yonetani, T., and Schatz, G. (1982b). Imported mitochondrial proteins cytochrome $b_{2}$ and cytochrome $c_{1}$ are processed in two steps. Proc. Natl. Acad. Sci. USA 79, 267-271.

Hackenbrock, C. R. (1968). Chemical and physical fixation of isolated mitochondria in low-energy and high-energy states. Proc. Natl. Acad. Sci. USA 61, 589-602.

Harmey, M. A., and Neupert, W. (1985). Intracellular transfer of mitochondrial membrane proteins. In The Enzymes of Biological Membranes, Volume 4, A. Martonosi, ed. (New York: Plenum Publ. Co.), pp. 431-464.

Hay, R., Böhni, P., and Gasser, S. (1984). How mitochondria import proteins. Biochim. Biophys. Acta 779, 65-87.

Hennig, B., Köhler, H., and Neupert, W. (1983). Receptor sites involved in posttranslational transport of apocytochrome $c$ into mitochondria: specificity, affinity and number of sites. Proc. Natl. Acad. Sci. USA 80 , 4963-4967.

Hurt, E. C., Pesold-Hurt, B., and Schatz, G. (1984a). The cleavable prepiece of an imported mitochondrial protein is sufficient to direct cytosolic dihydrofolate reductase into the mitochondrial matrix. FEBS Lett. 178, 306-310.

Hurt, E. C., Pesold-Hurt, B., and Schatz, G. (1984b). The aminoterminal region of an imported mitochondrial precursor polypeptide can direct cytoplasmic dihydrofolate reductase into the mitochondrial matrix. EMBO J. 3, 3149-3156

Kaput, J., Goltz, S., and Blobel, G. (1982). Nucleotide sequence of the yeast nuclear gene for cytochrome $c$ peroxidase precursor. Functiona implications of the pre-sequence for protein transport into mitochondria. J. Biol. Chem. 257, 15,054-15,058.

Kellems, R. E., Allison, V. G., and Butow, R. A. (1975). Cytoplasmic type $80 S$ ribosomes associated with yeast mitochondria. IV. Attachment of ribosomes to the outer membrane of isolated mitochondria. J. Cell Biol. 65, 1-14

Kolansky, D. M., Conboy, J. G., Fenton, W. A., and Rosenberg, L. (1982). Energy-dependent translocation of the precursor of ornithine transcarbamylase by isolated rat liver mitochondra. J. Biol. Chem. 257, 8467-8471.

Lambowitz, A. M., Smith, E. M., and Slayman, C. W. (1972). Electron transport in Neurospora mitochondria. Studies on wild type and poky. J. Biol. Chem. 247, 4850-4858.

Lämmli, V. K. (1970). Cleavage of structural proteins during the assembly of the head of bacteriophage T4. Nature 227, 680-685.

Laskey, R. A. (1980). The use of intensifying screens or organic scintillators for visualizing radioactive molecules resolved by gel electrophoresis. Meth. Enzymol. 65, 363-371.

McAda, P., and Douglas, M. G. (1982). A neutral metallo endoprotease involved in the processing of an F-ATPase subunit precursor in mitochondria. J. Biol. Chem. 257, 3177-3182.

Miura, S., Mori, M., Amaya, Y., and Tatibana, M. (1982). A mitochondrial protease that cleaves the precursor of ornithine carbamoyl transferase. Eur. J. Biochem. 122, 641-647.

Ohashi, A., Gibson, J., Gregor, I., and Schatz, G. (1982). Import of proteins into mitochondria. The precursor of cytochrome $c_{1}$ is processed in two steps, one of them heme-dependent. J. Biol. Chem. 257. 13,042-13,047.

Pelham, H. R. B., and Jackson, R. J. (1976). An efficient mRNAdependent translation system from reticulocate lysates. Eur. J. Biochem. 67, 247-256. 
Randall, L. L. (1983). Translocation of domains of nascent periplasmic proteins across the cytoplasmic membrane is independent of elongation. Cell 33, 231-240.

Sadler, J., Suda, K., Schatz, G., Kaudewitz, F., and Haid, A. (1984). Sequencing of the nuclear gene for the yeast cytochrome $c_{1}$ precursor reveals an unusually complex amino-terminal presequence. EMBO J. 3, 2137-2143

Schatz, G., and Butow, R. A. (1983). How are proteins imported into mitochondria? Cell 32, 316-318.

Schleyer, M., Schmidt, B., and Neupert, W. (1982). Requirement of a membrane potential for the posttranslational transfer of proteins into mitochondria. Eur. J. Biochem. 125, 109-116.

Schmidt, B., Wachter, E., Sebald, W., and Neupert, W. (1984). Processing peptidase of Neurospora mitochondria. Two step cleavage of imported ATPase subunit 9. Eur. J. Biochem. 144, 581-588.

Sebald, W., Neupert, W., and Weiss, H. (1979). Preparation of Neurospora crassa mitochondria. Meth. Enzymol. 55, 144-148.

Suissa, M., and Schatz, G. (1982). Import of proteins into mitochondria. Translatable mRNAs for imported mitochondrial proteins are present in free as well as mitochond ria-bound cytoplasmic polysomes. J. Biol. Chem. 257, 13,048-13,055

Takeda, M., Vassarotti, A., and Douglas, M. (1985). Nuclear genes coding the yeast mitochondria adenosine phosphatase complex: primary sequence analysis of ATP2 encoding the $F_{1}$-ATPase $\beta$-subunit precursor. J. Biol. Chem., in press.

Teintze, M., Slaughter, M., Weiss, H., and Neupert, W. (1982). Biogenesis of mitochondrial ubiquinol: cytochrome $\mathrm{c}$ reductase (cytochrome bc ${ }_{1}$ complex). J. Biol. Chem. 257, 10,364-10,371.

Van Venetie, R., and Verkleij, A. K. (1982). Possible role of non-bilaye lipids In the structure of mitochondria. A freeze fracture electron $\mathrm{ml}$ croscopy study. Biochim. Biophys. Acta 692, 397-405.

Wakabayashi, S., Matsubara, H., Kim, C. H., Kawai, K., and King, T. E. (1980). The complete amino acid sequence of bovine heart cytochrome $c_{1}$. Biochem. Biophys. Res. Commun. 97, 1548-1554.

Wojtczak, L., and Zaluska, H. (1969). On the impermeability of the outer mitochondrial membrane to cytochrome c. I. Studies on whole mitochondria. Biochim. Biophys. Acta 193, 64-72.

Zimmermann, R., and Neupert, W. (1980). Transport of proteins into mitochondria: posttranslational transfer of ADPIATP carrier into mitochondria in vitro. Eur. J. Biochem. 109, 217-229.

Zwizinski, C., and Neupert, W. (1983). Precursor proteins are transported into mitochondria in the absence of proteolytic cleavage of the additional sequences. J. Biol. Chem. 258, 13,340-13,346.

Zwizinski, C., Schleyer, M., and Neupert, W. (1983). Transfer of proteins into mitochondria. Precursor to the ADP/ATP carrier blnds to receptor sites on isolated mitochondria. J. Biol. Chem. 258, 4071-4074.

Zwizinski, C., Schleyer, M., and Neupert, W. (1984). Proteinaceous receptors for the import of mitochondrial precursor proteins. J. Biol. Chem. 259, 7850-7856. 